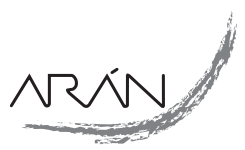

Editorial

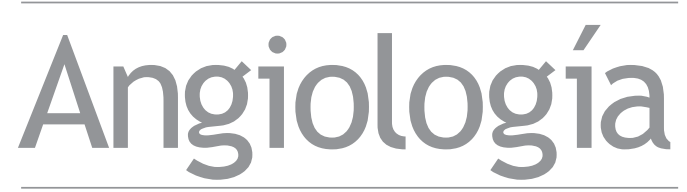

DOl: http://dx.doi.org/10.20960/angiologia.00015

\title{
El inicio de una nueva etapa
}

\section{The beginning of a new stage}

Con este número de la revista damos inicio a una nueva etapa. Una etapa ilusionante y con importantes ideas de cambio que pueden revertir en beneficio de la propia Sociedad Española de Angiología y Cirugía Vascular (SEACV). No solo cambiamos de editorial, sino que Arán Ediciones posibilitará la edición electrónica abierta, con lo que cumpliremos uno de nuestros objetivos: abrirnos al mundo y a la nueva era digital.

También hemos profesionalizado la publicidad: seguirá ligada a la dirección de la revista (y, por tanto, a la SEACV) y velará por esa difícil relación comercial entre las distintas compañías farmacéuticas y de nuevos materiales protésicos, que nos obliga a una dedicación y tiempo del que nosotros carecemos para llegar a hacerla de nuevo rentable.

El nuevo contrato con Arán Ediciones también nos permitirá reeditar el número especial del Congreso -que había dejado de publicarse por sus elevados costes- como un suplemento especial de Angiología, lo que ayudará a que los autores puedan referenciar ese trabajo. Asimismo, la ampliación contractual de hasta 80 páginas por número nos permitirá que muchas de las guías, consensos, capítulos o secciones de la SEACV puedan ver la luz no solo en formato on line, sino también en papel.

Todo cambio supone asumir un cierto riesgo, pero deseamos que este cambio sea para mejor. Desde aquí animamos a todos a la participación y a hacer de esta ilusión una realidad.

Valentín Fernández Valenzuela Presidente de la SEACV 